British Heart Fournal, 1979, 42, 35-42

\title{
Treatment of hypertrophic obstructive cardiomyopathy with verapamil
}

\author{
M. KALTENBACH, R. HOPF, G. KOBER, W.-D. BUSSMANN, M. KELLER, \\ AND Y. PETERSEN
}

\begin{abstract}
From Zentrum der Inneren Medizin, Abteilung für Kardiologie Klinikum der f. W. Goethe-Universität Frankfurt/M, Germany
\end{abstract}

SUMMARY Twenty-two patients with hypertrophic obstructive cardiomyopathy were treated with the calcium inhibitor, verapamil, which was administered in a mean oral dose of $480 \mathrm{mg}$ per day. After an average of 15 months of treatment (4 to 24 months), the QRS amplitude in the electrocardiogram was significantly reduced from 4.2 to $3.8 \mathrm{mV}$. Heart volume calculated from chest $x$-ray films in the supine position decreased significantly from 858 to $766 \mathrm{ml}$ per $1.73 \mathrm{~m}^{2}$. In 10 patients, follow-up heart catheterisation showed a decrease in left ventricular muscle mass in 7 patients and a slight increase in 3 patients. Coronary artery diameter decreased in 7 patients, increased in 1 , and was unchanged in 2 . The reduction in coronary artery diameter is considered to be a consequence of a reduced heart muscle mass. From all available clinical data it is concluded that verapamil treatment is superior to beta-blocker therapy.

Hypertrophic obstructive cardiomyopathy (HOCM), first described in the last century, is now often diagnosed. Medical treatment with beta-blockers, especially with propranolol, has been in use for more than 10 years. Long-term follow-up, however, has cast considerable doubt on the effectiveness of this therapy. It seems that the progression of the disease cannot be stopped and that a recurrence of symptoms is common (Edwards et al., 1970; Goodwin, 1970; Hubner et al., 1973; Stenson et al., 1973; Morrow et al., 1975; Loogen et al., 1976; Rothlin et al., 1976; Sowton, 1976).

Experimentally, it has been shown that certain forms of cardiomyopathy can be prevented with calcium inhibitor drugs. This was shown for the hereditary cardiomyopathy of the Syrian hamster (Lossnitzer, 1975). Recently, similar findings were reported in the cardiomyopathy induced by doxorubicin (Daniels et al., 1976). Though there are differences between experimentally induced cardiomyopathy and that found in humans, the myocardial damage may be the consequence of a similar mechanism in which the calcium ion plays an important role (Fleckenstein, 1969; Witzke and Kaye, 1976; Wrogemann and Pena, 1976).

Patients with HOCM may have a remarkably high left ventricular contractility even in the advanced stages of the disease. Their sensitivity to

Received for publication 30 March 1978 catecholamines and to digitalis is also well known. These features of the disease may be related to an increased availability of intracellular calcium. After a pilot study, a clinical trial with the calcium inhibitor, verapamil, was initiated (Kaltenbach et al., 1976).

\section{Methods}

Twenty-two patients, 18 men and 4 women, aged 19 to 44 years, were studied. Informed consent was obtained from all patients.

Symptoms were evaluated by means of a questionnaire. Electrocardiograms were recorded every 3 months with special attention to accurate calibration. In addition, phonocardiograms, carotid pulse tracings, and $\mathbf{M}$ mode echocardiograms (Picker System) were recorded.

Heart volume, calculated from chest $x$-rays films in the supine position at a tube-film distance of $2 \mathrm{~m}$ (Klepzig and Frisch, 1965), was determined every 6 months. In addition, conventional chest $x$-ray films in the standing position were taken. Before treatment with verapamil, right and left heart catheterisation was done in all patients, and selective coronary arteriograms (Sones technique) and biplane cine left ventriculograms were obtained. Right ventriculograms were taken only when a systolic pressure gradient was recorded within the right ventricle. 
In 10 patients, right and left heart catheterisation was repeated after 14 to 24 months (average 19 months) treatment with verapamil. The follow-up study also included selective coronary arteriography and ventriculography. In addition, left ventricular contractility was studied at rest and during exercise by means of a Millar double-tip catheter. The patients were exercised for 6 minutes on a bicycle ergometer in the supine position at a workload of 50 to 100 watts. After recovery from the first exercise test, $10 \mathrm{mg}$ verapamil was injected intravenously and a second exercise test was performed using the same workload and the same duration of exercise. Pressure and contractility ( $\mathrm{dP} / \mathrm{dt} \max$ and $\mathrm{dP} / \mathrm{dt} / \mathrm{P}$ ) were recorded through the Millar catheter, with one transducer in the apex and the other in the outflow tract of the left ventricle. Contractility reserve is defined as the difference between $\mathrm{dP} / \mathrm{dt}$ max at rest and $\mathrm{dP} / \mathrm{dt}$ max during exercise.

Coronary artery diameters were measured in different sites from the cineangiograms using a TV camera mounted on a cineprojector for high magnification. Left ventricular muscle mass was calculated from left ventricular free wall and left ventricular end-diastolic volume. Left ventricular enddiastolic volume and left ventricular end-systolic volume were determined from outlines of the left ventricle in two planes (RAO $40^{\circ}$ and LAO $50^{\circ}$ ). For these calculations, Simpson's rule using the computer system 'Volumat' (Siemens) was applied. $X$-ray magnification factor was determined (Kaltenbach et al., 1975) and used for calculation of coronary diameter, left ventricular volume, and left ventricular muscle mass (see Fig. 5).

\section{Medication}

Before the study, most patients had been treated for several months or years with beta-blocking agents, such as propranolol (120 to $240 \mathrm{mg}$ per day) or pindolol ( 7.5 to $15 \mathrm{mg}$ per day). In patients receiving a beta-blocker this treatment was stopped for at least one week before verapamil ${ }^{1}$ was started. After one week of treatment with verapamil $80 \mathrm{mg}$ t.d.s., the dose was increased to $160 \mathrm{mg}$ t.d.s. ( $480 \mathrm{mg}$ per day). In some patients, the dose was further increased after several months to $720 \mathrm{mg}$ per day. The drug was always administered orally.

\section{Statistical methods}

Student's t test was used to analyse the differences in the mean values before and after treatment. The criterion of significance was $P<0.05$. Every patient served as his own control.

${ }^{1}$ Knoll AG, Pharmaceuticals, D-6700 Ludwigshafen, West Germany. 


\section{Results}

\section{SYMPTOMS}

Sixteen patients were symptomatic. Eleven of these patients reported lessening or complete relief of chest pain or breathlessness on effort. Six patients had only minor subjective symptoms and noticed no essential change during treatment.

\section{HEART RATE AND BLOOD PRESSURE}

The average heart rate decreased from 68 to 65 beats/min. Statistically, this difference was not significant. Blood pressure fell to normal in one patient with moderate hypertension during treatment with verapamil. No change was observed in the remaining patients.

\section{ELECTROCARDIOGRAM}

After an average period of treatment of 15 months (4 to 24 months) a significant reduction in QRS amplitude was observed. The average Sokolow index (sum of maximal $\mathbf{S}$ and $\mathbf{R}$ deflections in leads $\mathrm{V} 1$ to V6) decreased from 4.2 to $3.8 \mathrm{mV}$. Twelve patients showed a decrease in QRS amplitude, in 5 patients this was unchanged, and 3 patients showed an increase in amplitude. The reduction of $Q R S$ amplitude was accompanied by a tendency for ST segments to return towards normal; Fig. 1 shows a typical example. The changes in QRS amplitude during treatment with verapamil were compared

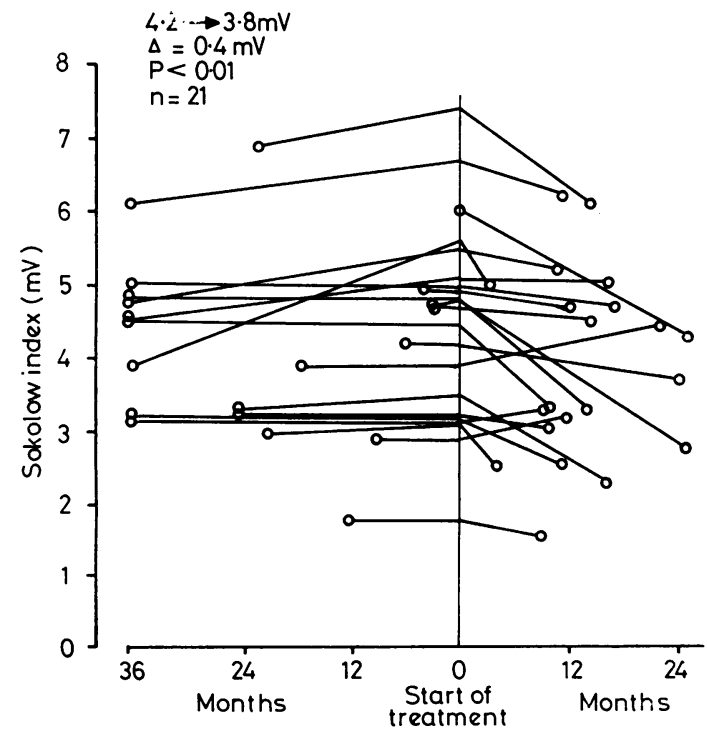

Fig. 2 Sokolow index in the praecordial electrocardiogram before and during verapamil treatment. with the values during previous treatment with beta-blockers (Fig. 2). During treatment with beta-blockers most patients had shown an unchanged or even increased QRS amplitude. In contrast, a distinct decrease was observed during verapamil treatment.

\section{PHONOCARDIOGRAM, CAROTID PULSE, AND ECHOCARDIOGRAM}

The systolic murmur of HOCM did not disappear during treatment with verapamil, but in some patients there was a decrease in intensity of the murmur. Carotid pulse tracings showed no significant change. No conclusions can be drawn from a limited number of echocardiographic studies.

\section{CHEST $x$-RAY AND HEART VOLUME}

Heart volume was calculated in 21 patients from chest $x$-ray films in the supine position. Measurements made before and after an average of 14 months treatment ( 2 to 24 months) are shown in Fig. 3. On average, heart volume decreased from 858 to $766 \mathrm{ml}$ per $1.73 \mathrm{~m}^{2}$; in 16 patients there was a decrease, in 3 patients an increase, and in 2 no change in heart volume. Conventional chest $x$-ray films in the standing position showed no essential change, and there were no signs of pulmonary congestion.

\section{HEART CATHETERISATION}

Catheterisation data obtained in 10 patients at the second study were compared with those obtained at the first catheterisation (Table). In 4 patients, this had been performed more than one year before the beginning of treatment with verapamil.

In 5 patients the systolic pressure gradient in the left ventricle was smaller, in 2 it was unchanged, and in 1 it was greater. In 1 of the 10 patients, no gradient was present, and in 1 the

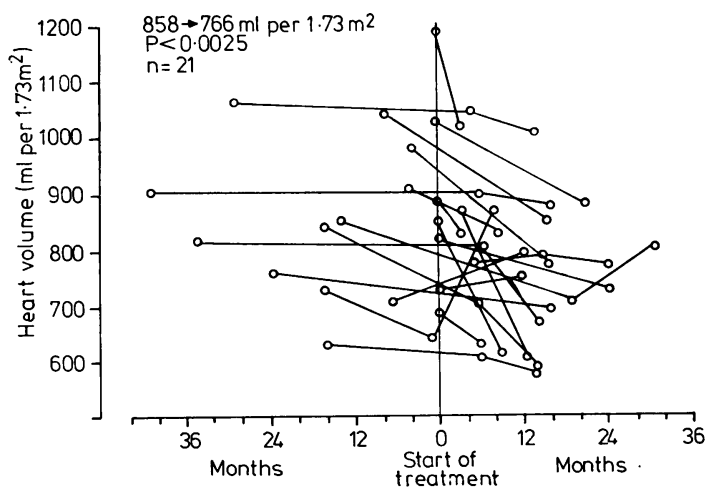

Fig. 3 Heart volume before and during verapamil treatment. 
Table Haemodynamic and other measurements before and after verapamil treatment

\begin{tabular}{|c|c|c|c|c|c|c|c|}
\hline Case no. & $\begin{array}{l}\text { Beginning of } \\
\text { verapamil } \\
\text { treatment }\end{array}$ & $\begin{array}{l}\text { Duration of } \\
\text { treatment } \\
\text { (mth) }\end{array}$ & & $\begin{array}{l}\text { es of } \\
\text { zeterisation }\end{array}$ & $\begin{array}{l}\text { LVEDV } \\
\left(\mathrm{ml} \text { per } 1.73 \mathrm{~m}^{2}\right)\end{array}$ & $\begin{array}{l}E F \\
(\%)\end{array}$ & $\frac{L V \text { muscle mass }}{\left(\mathrm{ml} \text { per } 1.73 \mathrm{~m}^{2}\right)}$ \\
\hline 1 & 6.1975 & 14 & $\begin{array}{l}\text { b } \\
\text { a }\end{array}$ & $\begin{array}{l}10.11 .1972 \\
31.8 .1976\end{array}$ & $\begin{array}{l}105 \\
142\end{array}$ & $\begin{array}{l}63 \\
63\end{array}$ & $\begin{array}{l}148 \\
101\end{array}$ \\
\hline 2 & 4.1975 & 15 & $\begin{array}{l}b \\
\text { a }\end{array}$ & $\begin{array}{l}7.3 .1974 \\
14.9 .1976\end{array}$ & $\begin{array}{l}85 \\
89\end{array}$ & $\begin{array}{l}78 \\
76\end{array}$ & $\begin{array}{l}122 \\
110\end{array}$ \\
\hline 3 & 9.1974 & 24 & $\begin{array}{l}\mathbf{b} \\
\mathbf{a}\end{array}$ & $\begin{array}{l}11.12 .1974 \\
7.9 .1976\end{array}$ & $\begin{array}{l}72 \\
95\end{array}$ & $\begin{array}{l}75 \\
85\end{array}$ & $\begin{array}{l}151 \\
104\end{array}$ \\
\hline 4 & 9.1974 & 24 & $\begin{array}{l}\mathbf{b} \\
\mathbf{a}\end{array}$ & $\begin{array}{l}\text { 19.8.1974 } \\
7.9 .1976\end{array}$ & $\begin{array}{l}149 \\
146\end{array}$ & $\begin{array}{l}88 \\
93\end{array}$ & $\begin{array}{l}154 \\
112\end{array}$ \\
\hline 5 & 3.1974 & 23 & $\begin{array}{l}\mathrm{b} \\
\mathrm{a}\end{array}$ & $\begin{array}{l}25.6 .1973 \\
27.9 .1976\end{array}$ & $\begin{array}{r}86 \\
90\end{array}$ & $\begin{array}{l}89 \\
88\end{array}$ & $\begin{array}{l}126 \\
138\end{array}$ \\
\hline 6 & 7.1975 & 16 & $\begin{array}{l}\mathrm{b} \\
\mathbf{a}\end{array}$ & $\begin{array}{l}26.3 .1975 \\
21.9 .1976\end{array}$ & $\begin{array}{l}201 \\
109\end{array}$ & $\begin{array}{l}80 \\
71\end{array}$ & $\begin{array}{l}417 \\
318\end{array}$ \\
\hline 7 & 4.1975 & 19 & $\begin{array}{l}\mathbf{b} \\
\mathbf{a}\end{array}$ & $\begin{array}{l}\text { 9.3.1972 } \\
23.11 .1976\end{array}$ & $\begin{array}{l}109 \\
131\end{array}$ & $\begin{array}{l}85 \\
86\end{array}$ & $\begin{array}{l}349 \\
296\end{array}$ \\
\hline 8 & 6.1975 & 17 & $\begin{array}{l}\mathbf{b} \\
\mathbf{a}\end{array}$ & $\begin{array}{l}29.5 .1972 \\
9.11 .1976\end{array}$ & $\begin{array}{r}80 \\
120\end{array}$ & $\begin{array}{l}89 \\
90\end{array}$ & $\begin{array}{r}91 \\
134\end{array}$ \\
\hline 9 & 5.1975 & 18 & $\begin{array}{l}\mathbf{b} \\
\mathbf{a}\end{array}$ & $\begin{array}{l}29.7 .1971 \\
9.11 .1976\end{array}$ & $\begin{array}{l}117 \\
179\end{array}$ & $\begin{array}{l}90 \\
91\end{array}$ & $\begin{array}{l}232 \\
301\end{array}$ \\
\hline 10 & 6.1975 & 15 & $\begin{array}{l}\mathbf{b} \\
\mathbf{a}\end{array}$ & $\begin{array}{l}11.12 .1974 \\
14.9 .1976\end{array}$ & $\begin{array}{r}98 \\
114\end{array}$ & $\begin{array}{l}90 \\
90\end{array}$ & $\begin{array}{l}250 \\
213\end{array}$ \\
\hline Average & & & $\begin{array}{l}\text { b } \\
\text { a }\end{array}$ & & $\begin{array}{l}110 \\
121\end{array}$ & $\begin{array}{l}82 \\
83\end{array}$ & $\begin{array}{l}204 \\
182\end{array}$ \\
\hline
\end{tabular}

measurement could not be repeated. As shown in Fig. 4, the gradient at rest and after provocation did not always change in the same manner.

Left ventricular muscle mass decreased in 7 patients and increased in 3 (Fig. 5). In the 3 patients with increased left ventricular muscle mass the first catheterisation had been performed 2 to 3 years before the beginning of verapamil treatment. A further increase of left ventricular muscle mass may have occurred before treatment with verapamil. Because of a pronounced reduction in wall thick-

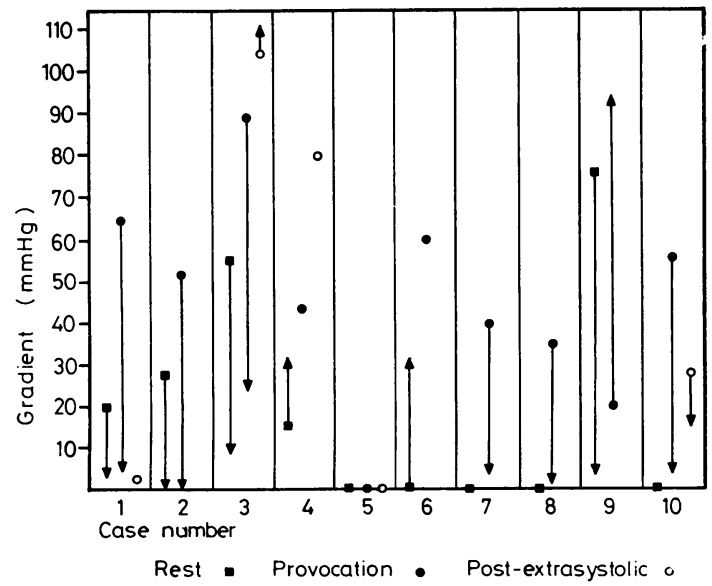

Fig. 4 Systolic pressure gradients within the left ventricle as measured at the times of the first and second catheterisation. Before verapamil, $\square=$ rest, $\mathrm{O}=$ provocation, $\bigcirc=$ post-extrasystolic. After verapamil, gradients shown by arrow ( $\uparrow$ or $\downarrow$ ). ness, muscle mass even decreased in some patients with increased left ventricular end-diastolic volume. Left ventricular end-diastolic pressure and ejection fraction were not affected by the treatment.

\section{SELECTIVE CORONARY ARTERIOGRAPHY}

Two independent investigators measured the coronary artery diameters at 5 different sites (Fig. 7). The investigators were not aware whether they were analysing the first or the second coronary arteriogram of a given patient. Correction was made for differences in $x$-ray magnification. Premedication was identical in all patients. Seven patients showed a decrease, 1 an increase, and 2 no change in coronary artery diameters (Fig. 7). On the average, both right and left coronary arteries were significantly reduced in diameter ( 8 and $9 \%$ respectively) and in cross-sectional area $(15$ and $17 \%)$. A typical example is shown in Fig. 8.

The results are summarised in the Table. In general there are parallel reductions in interventricular gradient, left ventricular muscle mass, QRS amplitude, heart volume, and coronary artery diameter, during oral verapamil treatment.

EFFECT OF INTRAVENOUS VERAPAMIL ON LEFT VENTRICULAR CONTRACTILITY

As verapamil can be shown to reduce contractility, 11 patients with HOCM were studied using a Millar double-tip catheter. Eight of these patients had been treated with oral verapamil before this investigation; 3 had not been treated. Haemodynamic measurements were made at rest and on exercise. After recovery, $10 \mathrm{mg}$ verapamil were given intra- 


\begin{tabular}{|c|c|c|c|c|c|c|c|c|c|c|}
\hline \multirow[b]{2}{*}{ hange) } & \multicolumn{2}{|c|}{ Coronary artery diameter } & \multicolumn{4}{|c|}{ Gradient $(m m H g)$} & \multicolumn{2}{|c|}{ Sokolow index } & \multicolumn{2}{|c|}{ Heart volume } \\
\hline & \multirow{2}{*}{$\begin{array}{l}(\mathrm{mm}) \\
5 \cdot 9 \\
4 \cdot 9\end{array}$} & \multirow{2}{*}{$\frac{(\% \text { change })}{-17}$} & \multicolumn{2}{|c|}{ Rest } & \multicolumn{2}{|c|}{ Provocation } & \multirow{3}{*}{$\begin{array}{l}(m V) \\
5 \cdot 3 \\
4 \cdot 7\end{array}$} & \multirow{2}{*}{$\frac{(\% \text { change })}{-11}$} & \multirow{2}{*}{$\begin{array}{l}(m l) \\
817 \\
669\end{array}$} & \multirow{2}{*}{$\frac{(\% \text { change })}{-18}$} \\
\hline & & & $\begin{array}{r}20 \\
4\end{array}$ & $\downarrow$ & $\begin{array}{r}65 \\
6\end{array}$ & $\downarrow$ & & & & \\
\hline & $4 \cdot 9$ & & 28 & & 52 & & & & 763 & \\
\hline & $4 \cdot 2$ & -14 & 0 & $\downarrow$ & 0 & $\downarrow$ & $2 \cdot 3$ & -34 & 694 & -9 \\
\hline & 3.8 & -5 & 56 & 1 & 89 & $\downarrow$ & 6.0 & -33 & 820 & -11 \\
\hline & 3.6 & -3 & 9 & $\downarrow$ & 24 & $\downarrow$ & $4 \cdot 0$ & -30 & 731 & -11 \\
\hline & 3.9 & 0 & 15 & $\uparrow$ & 43 & $=$ & $4 \cdot 2$ & 0 & 711 & -8 \\
\hline & 3.9 & 0 & 32 & $\uparrow$ & 43 & $=$ & $4 \cdot 2$ & 0 & 657 & -8 \\
\hline & $4 \cdot 2$ & & 0 & $=$ & 0 & $=$ & $2 \cdot 9$ & & 853 & -5 \\
\hline & $3 \cdot 1$ & -26 & 0 & $=$ & 0 & $=$ & $3 \cdot 1$ & +7 & 810 & -3 \\
\hline & $6 \cdot 0$ & -3 & 0 & $\uparrow$ & 60 & $=$ & $>5$ & & 1045 & -18 \\
\hline & $5 \cdot 8$ & -3 & 32 & $\uparrow$ & 60 & $=$ & 5 & - & 856 & -18 \\
\hline & $3 \cdot 4$ & & 0 & $=$ & 40 & 1 & $3 \cdot 2$ & & 645 & +26 \\
\hline & 3.4 & 0 & 0 & $=$ & 4 & $\downarrow$ & $2 \cdot 5$ & -22 & 872 & +26 \\
\hline & 5.0 & & 0 & & 35 & 1 & $5 \cdot 5$ & & 901 & \\
\hline & 4.5 & -10 & 0 & $=$ & 1 & $\downarrow$ & $5 \cdot 2$ & -5 & 880 & -2 \\
\hline & 2.9 & & 75 & & 20 & & $3 \cdot 6$ & & & \\
\hline & 3.4 & +15 & 4 & $\downarrow$ & 93 & $\uparrow$ & 4.9 & +27 & 960 & \\
\hline & $4 \cdot 1$ & -12 & 0 & $=$ & 56 & $\downarrow$ & $1 \cdot 7$ & +24 & 633 & -8 \\
\hline & 3.6 & 20 & 0 & - & 4 & 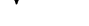 & $2 \cdot 1$ & $T 24$ & 581 & . \\
\hline
\end{tabular}

venously and a second exercise test was performed 10 minutes later. Left ventricular systolic and enddiastolic pressures fell from 147 to 132, and 20 to $16 \mathrm{mmHg}$, respectively. The intraventricular pressure gradient remained unchanged. The heart rate on exercise was significantly higher after verapamil. Contractility was unchanged after verapamil and this was so at rest as well as during exercise.

In contrast, beta-blocking drugs cause a distinct reduction in contractility at rest and a complete abolition of contractility reserve, as measured by identical methods.

\section{SIDE EFFECTS}

One patient had a first degree atrioventricular block with a PR interval of $0.3 \mathrm{~s}$ during administration of verapamil in a dose of $480 \mathrm{mg}$ per day. After reduction of the daily dose to $240 \mathrm{mg}$, the PR interval became normal. In the remaining patients there was no change in PR interval. Five patients complained of dizziness, nausea, headache, or chest pain during the first weeks of treatment. These symptoms disappeared while treatment continued.

\section{Discussion}

It is our clinical impression from this study that verapamil offers a better therapeutic approach to HOCM than the treatment with beta-blockers. Since most of the patients had been on conventional beta-blocker therapy before starting treatment with verapamil, the improvement in subjective and objective indices on verapamil could be compared with results of this preceding treatment. Because patients and investigators regarded beta-blockers as effective treatment, a placebo effect of verapamil seems unlikely. Subjective symptoms disappeared or lessened considerably in two-thirds of the patients who had been symptomatic on beta-blocker treatment. Usually, it took several weeks of treatment with verapamil before subjective improvement was noticed. The disappearance or lessening of left ventricular hypertrophy on the electrocardiogram was very impressive in some patients. In others, only slight changes were noted; this was particularly true for patients whose electrocardiograms did not show a typical left ventricular hypertrophy pattern. The improvement in the electrocardiogram was remarkable when compared with the finding of unchanged or increasing $\mathrm{QRS}$ amplitudes during treatment with beta-blockers.

Using chest $x$-ray films in the supine position, a significant decrease in heart size was noted, whereas conventional chest $x$-ray films showed no change in size or configuration of the heart. Radiographic signs of left ventricular failure were not observed during verapamil treatment. Since acute drug administration can influence heart size, all heart volume determinations were made 2 days after withdrawal of verapamil. The same procedure was adopted for heart volume determination during the preceding period of beta-blocker therapy. The diminished heart volume must therefore be attributed to a sustained reduction in heart size and not to an acute effect of verapamil. Since beta-blockade increases heart size, one could argue that the reduction in heart size might be attributed to a withdrawal of beta-blockers. However, the beta-blocker 


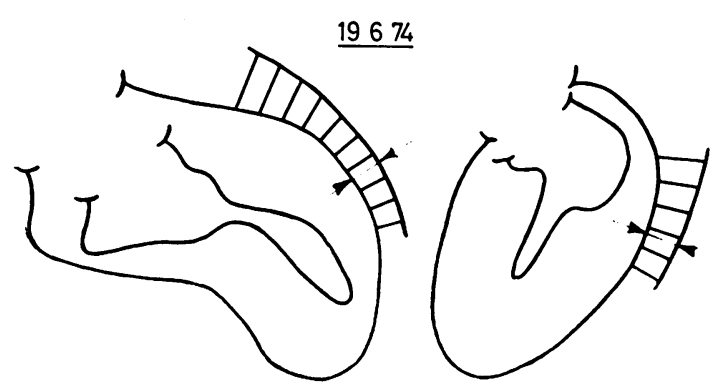

$-V_{E D V}: 149 \mathrm{ml}$ per $1.73 \mathrm{~m}^{2}$ EF: $88 \%$

LV muscle mass: $154 \mathrm{ml}$ per $1.73 \mathrm{~m}^{2}$

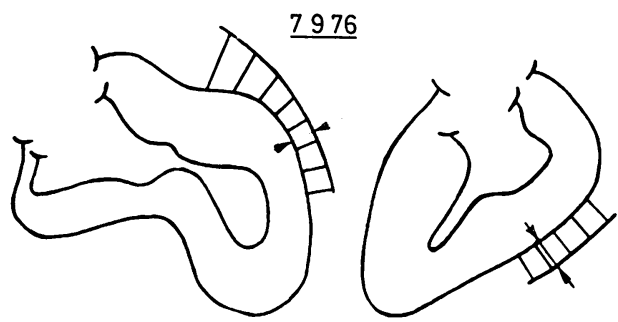

LV EDV: $146 \mathrm{ml}$ per $1.73 \mathrm{~m}^{2}$ EF: $93 \%$

LV muscle mass: $112 \mathrm{ml}$ per $1.73 \mathrm{~m}^{2}$

Fig. 5 End-diastolic and end-systolic contours (RAO and LAO views) of the left ventricle in a patient (case 4) before and after treatment. The wall thickness is shown outside the end-diastolic contour. Left ventricular muscle mass was calculated from end-diastolic volume and left ventricular wall thickness in the $R A O$ (anterior wall) and $L A O$ (posterior wall). After treatment, a decrease in left ventricular muscle mass is observed while there is little change in end-diastolic volume. Volume calculations were made applying Simpson's rule by means of a computer system. The $\mathrm{x}$-ray magnification was determined by observing the movement of the catheter tip located in the left ventricle when the $\mathrm{x}-$ ray table was moved a distance of $7 \mathrm{~cm}(19.6 .74)$ or $6 \mathrm{~cm}(7.9 .76)$.

was discontinued before the heart volume determination and the reduction in heart size occurred also in patients who were not on a beta-blocker before treatment with verapamil.

The left ventricular pressure gradients recorded at left heart catheterisation before and after verapamil treatment did not show the same consistent improvement as did the subjective symptoms, electrocardiogram, and heart volume, but pressure gradients often do not reflect the severity of the disorder. However, in several patients the first catheterisation had been done 1 to 3 years before verapamil treatment, and further deterioration may have occurred during this time.

When coronary artery diameters are measured all factors which can influence the dimensions of coronary arteries have to be taken into considera-

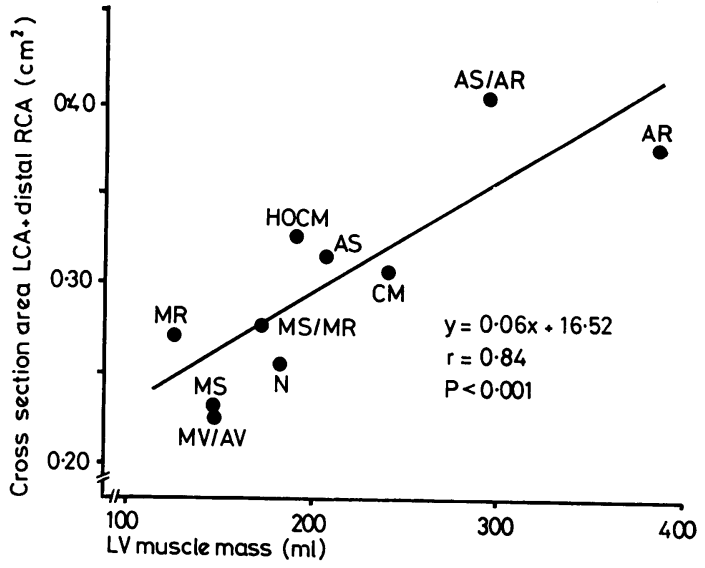

Fig. 6 Relation of coronary artery cross-section area and left ventricular muscle mass in different groups of patients (Kober et al., 1973). MS, mitral stenosis; MR, mitral regurgitation; $M V$, mitral valve disease; $A S$, aortic stenosis; $A R$, aortic regurgitation; $A V$, aortic valve disease; $C M$, cardiomyopathy; $N$, normal.

tion. Vasodilators, such as glyceryl trinitrate, increase coronary diameter (Gensini, 1975). A quantitative assessment of coronary artery dimensions is, therefore, only possible when the influence of any acutely administered drug can be ruled out. In addition, variations in $x$-ray magnification have to be taken into account. There was a genuine reduction in coronary artery cross-sectional area of about 16 per cent during treatment with verapamil, when measurements were made carefully observing all the above-mentioned precautions. In an earlier study (Kober et al., 1973), a direct relation between left ventricular muscle mass and coronary artery crosssectional area was shown (Fig. 6). It could, therefore, be assumed that the observed reduction in coronary artery dimension was the consequence of a decrease in ventricular muscle mass. This decrease in left ventricular muscle mass was confirmed by measurements computed from the left ventricular $N$ angiograms. The observation of a reduction of $N$ coronary artery diameter provides evidence of a re- $N$ duction in left ventricular hypertrophy by a method which is completely independent of all other measurements such as $Q R S$ voltage, heart volume, or left ventricular muscle mass determined angiocardiographically.

Whenever new drugs are administered, a drugfree interval is desirable to assess the efficacy of the new medication. In the present investigation, however, we chose not to interrupt the treatment; the subjective and objective changes following the change of treatment have to be interpreted in the light of the changes resulting from previous treat- 


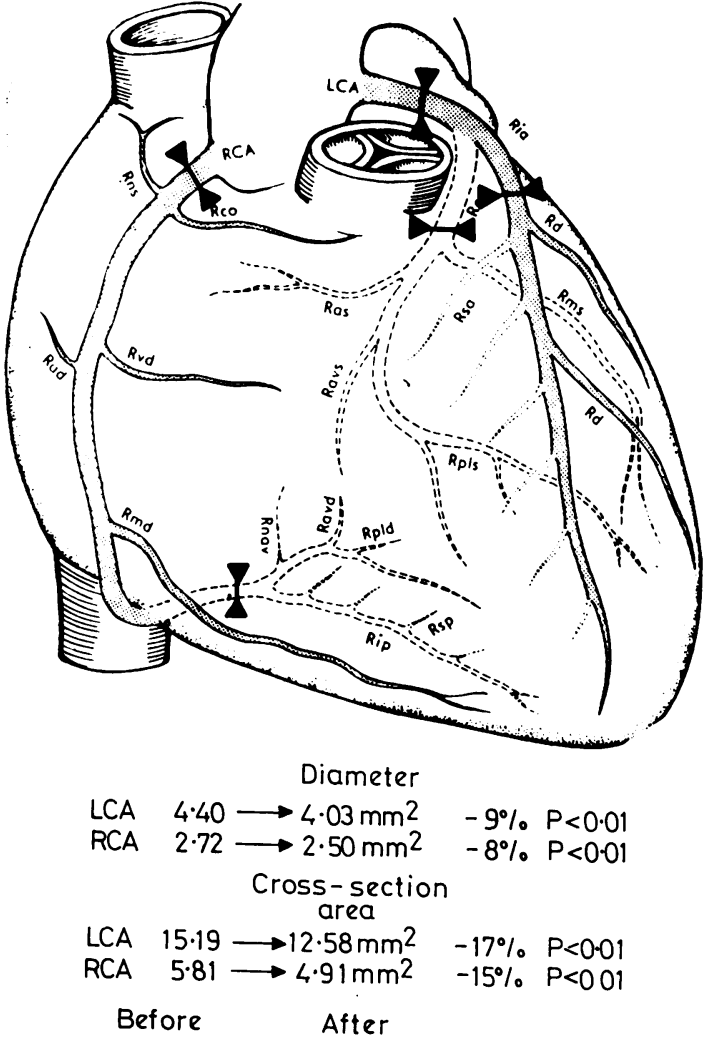

Fig. 7 Measurement of coronary artery diameter in 5 different locations. The reduction in diameter and cross-section area after verapamil treatment is calculated from mean values for the right $(R C A)$ and left $(L C A)$ coronary artery in 10 patients. ment with beta-blockers and its subsequent discontinuance. It might be argued that the dose of $240 \mathrm{mg}$ propranolol per day was not as high as some authors would have preferred. This dose, however, was not exceeded because testing of antianginal activity of beta-blockers by our own group had clearly shown that larger doses are only slightly more effective (Kaltenbach, 1977).

It is concluded from analysis of patients' symptoms, clinical data, and a variety of objective measurements that the treatment of HOCM with verapamil is effective and seems better than betablocker treatment.

In order to investigate the mechanism of action of the drug, we observed the acute effects of intravenous verapamil on left ventricular contractility and aortic and left ventricular pressures. There was no significant change in contractility, but left ventricular systolic pressure decreased slightly $(10 \%)$ and left ventricular end-diastolic pressure conspicuously (20\%).

This fall in left ventricular systolic and enddiastolic pressures points to a peripheral action of the drug, and is probably partly responsible for its beneficial action. On the other hand, however, it is also possible that the calcium inhibitor action with negative inotropic effect on the myocardium was obscured by a reflex sympathetic response induced by the fall in blood pressure.

It remains to be established which patients will respond best to verapamil, which patients may not respond, and which patients may require combined treatment with verapamil and beta-blockers. For this reason, we have initiated a multicentre cooperative study, in which one group of patients is

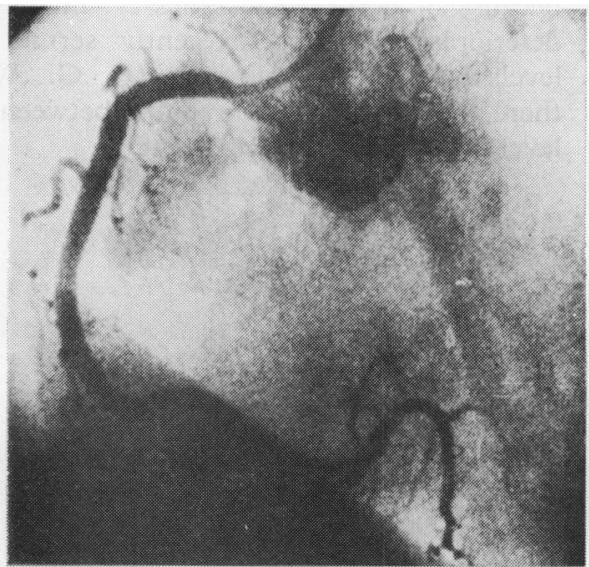

(A)
Before treatment

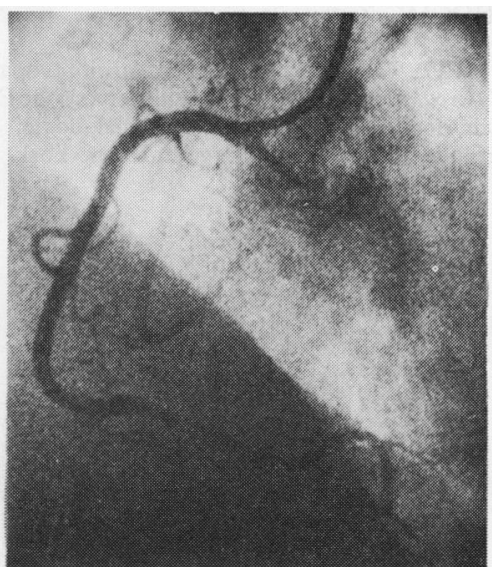

After treatment

Fig. 8 Example of reduction in coronary artery diameter in a 48-year-old man $(A)$ before treatment, $(B)$ after treatment. 
treated with verapamil and another matched group with beta-blockers, and which will probably give further information within the next two years.

\section{References}

Daniels, J. R., Billingham, M. E., Gelhart, A., and Bristow, M. R. (1976). Effect of verapamil and propranolol on adriamycin-induced cardiomyopathy in rabbits (abstract). Circulation, 53 and 54, 20.

Edwards, R. H. T., Kristinsson, A., Warrell, D. A., and Goodwin, J. F. (1970). Effects of propranolol on response to exercise in hypertrophic obstructive cardiomyopathy. British Heart fournal, 32, 219-225.

Fleckenstein, A. (1969). Myokardstoffwechsel und Nekrose. In Herzinfarkt und Schock, pp. 94-109, ed L. Heilmeyer and $\mathrm{H}$. J. Holtmeier. Thieme, Stuttgart.

Gensini, G. G. (1975). Coronary Arteriography. Futura, Mount Kisco, New York.

Goodwin, J. F. (1970). Congestive and hypertrophic cardiomyopathies. A decade of study. Lancet, 1, 731-739.

Hubner, P. J. B., Ziady, G. M., Lane, G. K., Hardarson, T., Scales, B., Oakley, C. M., and Goodwin, J. F. (1973). Double-blind trial of propranolol and practolol in hypertrophic cardiomyopathy. British Heart fournal, 35, 11161123.

Kaltenbach, M. (1977). Medikamentöse Therapie der koronaren Herzkrankheit. Arzneimittel-Forschung, 27, 703-707.

Kaltenbach, M., Hopf, R., and Keller, M. (1976). Calciumantagonistische Therapie bei hypertrophobstruktiver Kardiomyopathie. Deutsche medizinische Wochenschrift, 101, 1284-1287.

Kaltenbach, M., and Schulz, W. (1975). Kineangiographische Bestimmung von Ventrikelvolumina mit Rechnerhilfe. Deutsche medizinische Wochenschrift, 100, 590-593.

Klepzig, H., and Frisc'̀, P. (1965). Röntgenologische Herzvolumenbestimmung in Klinik und Praxis. Thieme, Stuttgart.

Kober, G., Spahn, G., Becker, H.-J., and Kaltenbach, M (1973). Weite und Querschnittsfläche der grössen, epikardialen Koronararterien bei Herzmuskelhypertrophie. Zeitschrift für Kardiologie, 63, 297.

Loogen, F., Krelhaus, W., and Kuhn, H. (1976). Verlaufsbeobachtungen der hypertrophischen obstruktiven Kardiomyopathie (HOCM). Zeitschrift für Kardiologie, 65, 511 521.

Lossnitzer, K. (1975). Genetic induction of cardiomyopathy. In Heart and Circulation, p. 309, ed J. Schmier and O. Eichler. Handbuch der experimentellen Pharmakolcgie, vol. 16 no. 3. Springer, Berlin, Heidelberg, and New York.
Morrow, A. G., Reitz, B. A., Epstein, S. E., Henry, W. L., Conkle, D. M., Itscoitz, S. B., and Redwood, D. R. (1975). $\stackrel{\leftarrow}{\leftarrow}$ Operative treatment in hypertrophic subaortic stenosis $\overrightarrow{\vec{F}}$ techniques and the results of pre- and postoperative assess- 9 ments in 83 patients. Circulation, 52, 88-102.

Rothlin, M., Arbenz, U., Krayenbühl, H. P., Turina, J., and $\bar{\sigma}$ Senning, A. (1976). Spätresultate nach Operationen bei $\bar{\sigma}$ muskulärer subvalvulärer Aortenstenose. Zeitschrift für Kardiologie, 65, 501-510.

Sowton, E. (1976). Beta-Rezeptorenblocker bei hypertropher Cardiomyopathie. In Die Beta-Blocker Gegenwart und Zukunft, p. 239, ed W. Schweizer. Huber, Bern.

Stenson, R. E., Flamm, M. D., jun, Harrison, D. C., and Hancock, E. W. (1973). Hypertrophic subaortic stenosis. Clinical and hemodynamic effects of long-term propranolol therapy. American fournal of Cardiology, 31, 763-773.

Witzke, D. J., and Kaye, M. P. (1976). Hypertrophic cardiomyopathy induced by administration of nerve growth ! factor (abstract). Circulation, 53 and 54, 88.

Wrogemann, K., and Pena, S. D. J. (1976). Mitochondrial calcium overload. A general mechanism for cell necrosis in $\mathrm{O}$ muscle diseases. Lancet, 1, 672-674.

Requests for reprints to Professor Martin Kaltenbach, Abteilung für Kardiologie, Zentrum der Inneren Medizin, Klinikum der J. W. GoetheUniversität, Theodor-Stern-Kai 7, 6000 Frankfurt/ M 70, West Germany.

\section{Addendum}

Since the submission of this paper for publication, the number of patients treated with verapamil has increased from 22 to 39 , and duration of follow-up now ranges from 1 to 100 months (mean 26.4 months). Experience with additional patients and longer follow-up confirms the reported favourable $\bar{q}$ results. In 4 patients, treatment was discontinued because of non-cardiac illnesses: in these patients deterioration ensued. Recently serum verapamil levels have been measured (B. G. Woodcock); 오 there appears to be a correlation between verapamil $D$ level and clinical improvement. 